\title{
TEORIA DOS CUSTOS DE MENSURAÇÃO NO SETOR AUTOMOTIVO
}

\author{
MEASUREMENT COSTS THEORY IN THE AUTOMOTIVE \\ SECTOR
}

\section{TEORIA DE LOS CUSTOS DE MENSURACIÓN EN EL SECTOR AUTOMOTRIZ}

\section{Cleiciele Albuquerque Augusto}

Professora Adjunta do Departamento de Administração da Universidade Estadual de Maringá (UEM) / Doutora em Administração pela Universidade Federal de Santa Catarina (UFSC) / Mestre em Administração pela Universidade Estadual de Maringá (UEM), Brasil

cleicielealbuquerque@yahoo.com.br

\section{José Paulo de Souza}

Professor Associado do Departamento de Administração da Universidade Estadual de Maringá (UEM), Brasil jpsouza@uem.br

\author{
Silvio Antonio Ferraz Cario \\ Professor Associado do Departamento de Economia da \\ Universidade Federal de Santa Catarina (UFSC) / \\ Doutor em Ciências Econômicas pela Universidade \\ Estadual de Campinas (UNICAMP) / Mestre em \\ Ciências Sociais pela Universidade Federal de Santa \\ Catarina (UFSC) / Mestre em Economia pela \\ Universidade Federal do Rio Grande do Sul (UFRGS), \\ Brasil \\ fecario@yahoo.com.br
}

Contextus

ISSNe 2178-9258

Organização: Comitê Científico Interinstitucional Editor Científico: Diego de Queiroz Machado

Avaliação: double blind review pelo SEER/OJS Edição de texto e de layout: Carlos Daniel Andrade Recebido em 27/08/2017

Aceito em 01/03/2018 $2^{\mathrm{a}}$ versão aceita em 22/03/2018

\section{RESUMO}

Esta pesquisa objetivou compreender como a escolha pelas estruturas de governança é realizada, considerando aspectos de mensuração, de direitos de propriedade e de disponibilidade de informações nas relações de montadoras e seus fornecedores diretos de autopeças. Para tanto, traçou-se uma pesquisa teórico-empírica, qualitativa e descritiva. Foram realizadas entrevistas semiestruturadas com os gerentes de logística, de compras e de qualidade das montadoras, localizadas no estado do Paraná, bem como com os gerentes de logística de empresas fornecedoras diretas e coordenadores da indústria automotiva da Federação das Indústrias no Estado do Paraná (FIEP). Dentre os resultados, constatou-se que a integração vertical se dá na presença de ativos específicos (design, estamparia, motor e câmbio) que apresentam elevada dificuldade de mensuração por envolverem a identidade das montadoras. Observou-se também que as demais autopeças, mesmo com elevada especificidade, são transacionadas pela contratação, desde que não apresentem dificuldades de mensuração. Conclui-se então que o nível de especificidade não é suficiente para explicar as decisões pelas estruturas de governança no setor, indicando a necessidade de considerar aspectos de mensuração para obter adequada compreensão de suas fronteiras.

Palavras-chave: Estruturas de Governança. Mensuração. Direitos de propriedade. Setor automotivo.

\begin{abstract}
This research aims to understand how the choice of governance structures is performed, considering aspects of measurement, property rights and availability of information in the relations of automakers and their direct auto parts suppliers. For that, a theoretical-empirical research, of qualitative nature and descriptive type, was drawn. Semi-structured interviews were conducted with: logistics, purchasing and quality managers of the automakers
\end{abstract}


located in the state of Paraná; logistics managers of their direct suppliers; and automotive industry coordinators from the Industrial Federation of the State of Paraná (FIEP). Among the results, it was verified that the vertical integration occurs in the presence of specific assets (design, stamping, engine and gearbox) which present a high measurement difficulty because they are associated with automakers identity. Other auto parts, even with high specificity, are acquired under agreement with suppliers, when they do not present measurement difficulties. It was concluded that the level of specificity is not sufficient to explain the governance structures decisions in the sector, indicating the need to consider measurement aspects to obtain an appropriate understanding of its borders. Keywords: Governance Structures. Measurement. Property rights. Automotive industry.

\section{RESUMEN}

Esta investigación tiene como objetivo comprender cómo se realiza la elección de las estructuras de gobierno, considerando aspectos de medición, derechos de propiedad y disponibilidad de información en las relaciones de los fabricantes de automóviles y sus proveedores directos de autopartes. Para ello, se realizó una investigación teórico-empírica, de naturaleza cualitativa y de tipo descriptivo. Se realizaron entrevistas semiestructuradas con los gerentes de logística, de compras y de calidad de las montadoras en el Estado de Paraná, y también con gerentes de logística de empresas de transporte y directivos de la industria automotriz de la Federación de las Industrias en el Estado de Paraná (FIEP). Se verificó que la integración vertical se produce en presencia de activos específicos (design, estampación, motor y caja de cambios) que presentan una gran dificultad de medición por estar asociados con la identidad de los fabricantes de automóviles. Otras piezas de automóviles, incluso con alta especificidad, se adquieren por contratación cuando no presentan dificultades de medición. Se concluyó que el nivel de especificidad no es suficiente para explicar las decisiones de las estructuras de gobierno en el sector, lo que indica la necesidad de considerar los aspectos de medición para obtener una comprensión adecuada de sus fronteras.

Palabras-clave: Estructuras de Gobierno. Mensuración. Derechos de propiedad. Sector automotivo.

\section{INTRODUÇÃO}

A escolha estratégica por internalizar a produção ou contratar fornecedores de autopeças faz parte da história da organização produtiva das montadoras automotivas. Estudos têm mostrado que, enquanto alguns componentes ainda se mantêm sob o controle produtivo das montadoras, a maioria é adquirida por meio de contratos com diversos fornecedores de autopeças (CERRA; MAIA, 2008; COSTA; HENKIN, 2016; FERREIRA; SERRA, 2010; FERRATO et al., 2006; TORRES, 2011; VANALLE; SALLES, 2011).

A discussão sobre as decisões de internalizar ou externalizar a produção, por meio de produção própria (integração vertical), contratos e a compra no mercado livre, tem sua inspiração em Coase (1937). Constatando a existência de custos de transação, ao lado dos de produção, Coase (1937) indica que as firmas nascem como alternativa para minimizar os custos de transações que existiriam nas negociações via mercado. Nessa perspectiva, dentre as abordagens que buscam investigar as motivações para internalizar ou externalizar a produção, destacam-se a Teoria dos Custos de Transação ou TCT (COASE, 1937; KLEIN; CRAWFORD; ALCHIAN, 1978; WILLIAMSON，1975; 1985; 1996; 1999; 2000; 2002; 2008; ZYLBERSZTAJN, 1995; 2009) e a Teoria dos Custos de Mensuração ou TCM 
(BARZEL，2002; 2003; 2005; COASE, 1937; MÉNARD; SHIRLEII, 2014; ZYLBERSZTAJN, 2005; 2009).

Conforme a TCT, a escolha pela produção interna ocorre quando existe elevado nível de especificidade de ativos, com a consequente possibilidade de comportamento oportunista e com a justificável opção pelo controle do processo produtivo (COASE, 1937; DAVID; HAN, 2014; KLEIN et al., 1978; MAHNKE; OVERBY; VANG， 2005; WILLIAMSON，1975; 1985; 1996). A escolha pelas contratações, por sua vez, justifica-se na presença de níveis moderados de investimentos em ativos específicos, capazes de conter o oportunismo sem os custos extras da integração vertical (WILLIAMSON, 1985).

Nota-se assim que a integração vertical, apesar de mais custosa, possibilita controle e rápida adequação ao mercado, ao passo que a contratação permite reduzir custos de transação, algo relevante para competir no setor. Desse modo, o nível dos ativos específicos justificaria essa escolha, nos termos da TCT (WILLIAMSON, 1975; 1985). Barzel (2005), por sua vez, ao tratar de estruturas de governança à luz da TCM, propõe que a escolha da estrutura de governança deve basear-se na dificuldade ou facilidade de mensurar os atributos dos ativos como unidade de análise: "a noção de custo de medição é mais geral do que a de ativos específicos. Também é mais operacional” (BARZEL, 2005, p. 372, tradução nossa).

No setor automotivo, quando se consideram as dimensões mensuráveis do ativo, apresentam-se novas percepções de análise acerca da escolha da estrutura de governança. Considerando a TCM, essas percepções estão relacionadas, segundo Barzel (2002), à capacidade de mensuração dos atributos dos bens transacionados. Além de indicar a opção pela estrutura de governança mais adequada, a mensurabilidade dos atributos dos bens lança um olhar sobre os direitos de propriedade envolvidos na troca, já que o controle sobre esses atributos diminui a possibilidade de apropriação de valor (BARZEL， 1997; 2002; 2005). Nesse âmbito, o autor ainda destaca a informação como aspecto fundamental, pois reduz as assimetrias, minimizando a possibilidade de perdas nas transações realizadas.

Diante disso, questiona-se: como se dá a escolha pela utilização da integração vertical e da contratação, no setor automotivo, quando se leva em conta a TCM para aquisição das autopeças? Assim, a presente investigação objetiva compreender como a escolha pelas estruturas de governança é realizada, 
considerando a influência da mensuração, dos direitos de propriedade e da informação nas relações entre montadoras e seus fornecedores diretos de autopeças.

Ao trazer a perspectiva da TCM, o presente estudo contribui para lançar um novo olhar sobre a decisão de integrar ou contratar fornecedores. Como a TCM é relativamente recente, estudos empíricos são relevantes para que os pressupostos teóricos sejam divulgados e validados no âmbito de diferentes sistemas produtivos. Ademais, embora a TCT seja tradicionalmente a principal referência para estudos associados aos limites das organizações, a TCM pode contribuir como modelo alternativo ou, até mesmo, complementar.

A intenção é abrir perspectivas para construir um referencial com maior poder de compreensão das escolhas sobre estruturas de governança. Para atingir o objetivo proposto, além dessa introdução, no segundo capítulo apresenta-se o referencial teórico utilizado sobre a TCM. O terceiro capítulo apresenta os procedimentos metodológicos, enquanto o quarto se dedica a analisar os resultados obtidos. No quinto capítulo, são realizadas as conclusões, seguidas das referências utilizadas.

\section{TEORIA DOS CUSTOS DE MENSURAÇÃO E ESTRUTURAS DE GOVERNANÇA}

A discussão teórica envolvendo os custos de mensuração tem origem no trabalho de Ronald Coase, de 1937, intitulado The Nature of the Firm. Da proposta de Coase, surgiram, a partir da década de 1970, os trabalhos de Williamson (1975; 1985; 1996) e North (1990; 1991; 2006), consolidando a denominada Nova Economia Institucional (NEI). Segundo Williamson (2008) e Zylbersztajn (2009), a NEI propõe duas vertentes analíticas complementares, uma macroanalítica e uma micro. Aquela concentra-se na origem, estruturação e mudanças das instituições, bem como na sua participação no desenvolvimento econômico (NORTH, 1991; ZYLBERSZTAJN, 2009). A microanalítica, por sua vez, volta-se para a análise de estruturas de governança, contemplando duas abordagens: a TCT e a TCM (WILLIAMSON, 1985 ; ZYLBERSZTAJN, 2005). No tratamento das estruturas de governança com base na noção da mensuração, Barzel (2005) indica alguns pontos fundamentais com impacto nessas estruturas: a mensuração, os direitos de propriedade e a informação, tratados nesta seção. 


\subsection{Mensuração}

A mensuração, de acordo com Barzel (2003), trata das garantias de direitos de propriedade, considerando as dimensões físicas dos atributos do ativo transacionado (tamanho, quantidade, cor, peso, dentre outros). Nessa linha, Barzel (1997) indica que o elevado custo de obter uma mensuração exata e abrangente de um conjunto de atributos específicos e não uniformes resulta na incompletude contratual. Isso, aliado ao comportamento maximizador dos agentes, cria oportunidades para captura de valor.

Embora a dificuldade em mensurar todas as dimensões envolvidas torne $\mathrm{o}$ contrato incompleto, Barzel (1997; 2003) indica que o nível dessa dificuldade é que determina a estrutura de governança: a dificuldade de mensurar ou determinar os direitos de propriedade dos produtos transacionados levaria à integração vertical como mecanismo de proteção mais adequado. Caso a dificuldade de mensuração de um atributo declinar, mais atividades serão regidas pelo mercado por meio de contratos e menor será o número de atividades desempenhadas dentro de uma firma (MENARD; SHIRLEI, 2014; ZYLBERSZTAJN, 2005; VAZQUEZ; HALLACK, 2015). Assim, Barzel (2002, p. 5), por meio da TCM, oferece uma regra mais geral: “À medida que a delimitação dos direitos sobre quase-rendas torna-se mais fácil, escrever contratos fica mais fácil, assim, o incentivo para integrar é reduzido".

Nesse contexto, o custo de mensuração caracteriza um custo de transação (ITO; ZYLBERSZTAJN, 2016). Barzel (1997, p. 2) verifica que a mensuração tem um custo, que surge a partir de recursos utilizados para estabelecer e manter direitos de propriedade: "Custos de transação referemse aos custos associados com a transferência, captura e proteção de direitos". Sob a ótica do direito de propriedade, então, os custos de transações estão relacionados ao delineamento e garantia da propriedade sobre ativos específicos (CUNHA; SAES; MAINVILLE， 2015; MÉNARD; SHIRLEI, 2014; ITO; ZYLBERSZTAJN, 2016). Para Barzel (2003), se os custos de transação são zero, significa que os direitos de propriedade são perfeitamente mantidos. Custos de transação positivos implicam, portanto, em custos de garantia de direito econômico sobre um ativo (BARZEL，2005; MÉNARD; SHIRLEI, 2014). Assim, o aspecto chave dos custos de transação, na perspectiva da TCM, está na mensurabilidade dos atributos dos bens. 
Assim, na proposição de Barzel (2005), organizações integradas surgem quando o custo de mensurar produtos transacionados é alto. No caso das dimensões com custos de mensuração baixos, Barzel (2003; 2005) afirma que elas podem ser garantidas pela lei e, assim, realizadas fora da firma; ocorrendo distorções, o adquirente pode acionar o provedor, que deve fornecer garantias para o produto. Além de custos altos e baixos de mensuração, uma terceira situação pode ocorrer quando os custos de mensuração são mais difíceis de serem definidos. Nesse caso, as partes podem se organizar privadamente para diminuir os riscos de perda de eficiência na transação, se valendo de mecanismos de reputação dos agentes, ou de laços sociais, ou ainda realizando a transação internamente (BARZEL, 2005).

Como sugerem Poppo e Zenger (1998), a precisão na mensuração simplesmente define a performance dos dispositivos de governança, externa e internamente. Internamente, quando a mensuração se torna problemática, os gestores podem adotar autoridade $\mathrm{e}$ monitoramento de comportamento (POPPO; ZENGER, 1998; VAZQUEZ; HALLACK, 2015). Já nos mercados, falta a capacidade para tal intervenção gerencial, assim: "Quando a mensuração é altamente problemática, os mercados simplesmente falham" (POPPO; ZENGER, 1998, p. 859, tradução nossa). Alternativamente, quando a performance é medida precisamente, mercados entregam alto poder de incentivo via preço.

\subsection{Direitos de propriedade}

North (2016) indica que os direitos de propriedade juntamente com as instituições, são determinantes da eficiência dos mercados. Nas transações, de forma particular, Barzel (1982; 1997) argumenta que os bens são compostos de "atributos", ou seja, diferentes funcionalidades e usos, e os direitos de propriedade são definidos a partir desses atributos. A necessidade de definir e mensurar os múltiplos atributos estabelece situações em que a complexidade e a incerteza são relevantes na transação (CUNHA; SAES; MAINVILLE, 2015). Essa relevância se justifica pelo fato dos custos de mensuração permitirem situações oportunistas, em que pode ocorrer a captura de atributos não mensurados (FIANI, 2003). Ademais, a possibilidade de transferência de erros entre as partes, pela ausência de mensuração (BARZEL, 2005), também configura comportamento 
oportunista, possibilitando apropriação de valor. Por isso, a noção de proteção dos direitos de propriedade ocupa lugar central na abordagem da TCM.

Segundo Barzel (2003), a abordagem de direitos de propriedade surgiu sob o reconhecimento de que transações envolvem a troca de direitos e não apenas a troca per se de bens. Como explicita Zylbersztajn (2009, p. 401): "Cada dimensão de uma transação representa uma troca de direitos de propriedade e pode ser caracterizada por um custo de mensuração, e traz determinado valor para os partícipes da transação". Nessa linha de raciocínio, Foss e Foss (2004) e Ito e Zylbersztajn (2016) afirmam que, ao analisar as transações, é mais útil pensar no que está sendo trocado no mercado como os direitos de propriedade, em vez de bens físicos por si só. Conforme esses autores, esses direitos são limitados, não só pela lei, mas também por normas e por outros mecanismos privados estabelecidos pelas partes envolvidas na transação.

A discussão de direitos de propriedade é apresentada na literatura a partir de duas vertentes, conforme explicitam Foss e Foss (2001): da "Velha Abordagem de Direitos de Propriedade" (ou OPRA - Old Property Rights Approach); da "Nova Abordagem de
Direitos de Propriedade" (NPRA - New Property Rights Approach).

O aparecimento da primeira vertente é marcado pelo trabalho pioneiro sobre a economia dos direitos de propriedade, apresentado por Coase (1960), intitulado The problem of social cost. Nesse trabalho, Coase afirma que a propriedade não fornece ao proprietário os direitos exclusivos de ativos, mas somente direitos para certos usos dos ativos. Nessa percepção, o foco não está sobre a propriedade em si, mas na atribuição de direitos de utilização. $\mathrm{O}$ artigo de Coase deu origem a uma série de trabalhos sobre os direitos de propriedade (ALCHIAN, 1977; ALCHIAN; DEMSETZ, 1972; BARZEL, 1982; 1987; 1994; 1997; 1999; CHEUNG, 1969; 1983; UMBECK, 1981), configurando a OPRA.

Da mesma maneira que o aparecimento da OPRA pode ser datada pela publicação de Coase (1960), o surgimento de NPRA se origina na publicação de Grossman e Hart (1986), marcando a forma como os modernos economistas formais pensam sobre a posse e os direitos de propriedade. A ideia central na NPRA é que a propriedade é a posse legalmente garantida de um ativo (ALMEIDA; ZYLBERSZTAJN, 2011). A consideração de que a propriedade é a posse do ativo indica a necessidade de 
distinguir direitos específicos de controle e direitos residuais de controle. Os primeiros podem ser delineados e diretamente atribuídos através de meios contratuais. Os direitos residuais de controle, por sua vez, são associados à posse do ativo, ou seja, são aqueles obtidos por meio da propriedade legal dos ativos (HART; MOORE, 1990). Esses direitos implicam, conforme Hart (1995, p. 371, tradução nossa): “[...] no direito para decidir o uso do ativo em contingências não contratadas". Assim, a importância econômica de propriedade pela NPRA decorre da capacidade do proprietário de exercer os direitos residuais de controle sobre os ativos.

Tanto os direitos de uso do ativo (OPRA), quanto os direitos de controle do ativo (NPRA) podem ser garantidos pelo direito legal (contratos formais), pelo direito econômico (acordos informais) e seus mecanismos de garantias (enforcement). $\mathrm{O}$ direito legal implica na garantia pelo Estado, referindo-se àquilo o que o Estado "garante" a um agente. O direito econômico é garantido privadamente, indicando a capacidade do agente de se apropriar dos resultados inerentes às propriedades de um ativo (BARZEL, 1997).

Nessa orientação, Barzel (2005, p. 358 , tradução nossa) explicita que direitos de propriedade se constituem em "[...] direitos econômicos sobre uma mercadoria, e eles indicam a habilidade para apreciar esta mercadoria direta ou indiretamente através da troca". Considerando que um produto é formado por diferentes atributos, direitos econômicos de propriedade podem ser atribuídos para cada atributo particular (MONTEIRO; ZYLBERSZTAJN, 2011; ITO; ZYLBERSZTAJN, 2016). Sendo assim, “[...] o direito econômico sobre o ativo em si pode ser entendido como o conjunto dos direitos econômicos referentes a cada atributo que o compõe" (MONTEIRO; ZYLBERSZTAJN, 2011, p. 101). Sob a ótica do direito de propriedade, os custos de transações, se relacionam diretamente ao delineamento e garantia da propriedade sobre ativos específicos.

Na visão de Klein et al. (1978, p. 298): "Depois que um investimento específico é realizado e a quase renda é criada, a possibilidade de comportamento oportunista é muito real". Seguindo a estrutura de Coase, esse problema pode ser resolvido de dois possíveis modos: integração vertical ou contratos. Firmas integradas nessas condições têm vantagem sobre os rivais. Barzel (1997, p. 2, tradução nossa) afirma que, nesse contexto, "[r]egimes de propriedade são determinados por custos, e custos são determinados pelo padrão de posse". 
Assim, conforme observam Hart e Moore (1990), os direitos de propriedade e de controle surgem como aspectos decisivos na escolha pela integração vertical ou contratos: se o objetivo é reduzir custos a partir de uma segunda firma, os contratos podem ser empregados; por outro lado, se a intenção é possuir controle, é preciso integrar as operações.

\subsection{Informação}

Os direitos de propriedade são intimamente influenciados pela informação que se tem sobre os aspectos transacionais, tais como preço, produto e salvaguardas. Sem informação, não há definição do que se possui. Dessa forma, a informação se apresenta como fundamental para garantir os direitos de propriedade, influenciando na integração ou não das atividades, como explica Barzel (2005, p. 358, tradução nossa): "Com nenhuma informação sobre a mercadoria, a composição da mercadoria e seu valor constituem-se caixas pretas. A informação é a chave para essas caixas pretas, que confere significado à propriedade". Notase, portanto, que a informação dá significado à posse (BARZEL, 2005).
Na visão de Vazquez e Hallack (2015), o ambiente econômico é caracterizado por informações privadas, ou seja, informações observadas apenas por um subconjunto de jogadores, e o objetivo é projetar regras que obtenham resultados eficientes. Essas regras são importantes, porque, conforme Caleman, Zylbersztajn, Pereira e Oliveira $(2017$, p. 57 , tradução nossa), "o valor criado pode ser associado a investimento em ativos específicos que podem levar à ocorrência de custos de transação, por estarem sujeitos a um ambiente de incerteza, assimetria informacional e racionalidade limitada dos agentes.

Dessa forma, Barzel (2003) indica que a informação é uma forma de mensuração e tem um custo de transação para ser gerada e transferida. Esses custos de transação surgem porque a informação é incompleta, custosa e assimetricamente mantida entre as partes nas transações (CHEREMUKHN; POPOVA; TUTINO, 2015; NORTH, 2016; VAZQUEZ; HALLACK, 2015).

Barzel (2003) explica que, ao se transacionar um produto, transfere-se também as informações relacionadas a esse produto, ainda que de forma parcial (informação incompleta). Com informação parcial, disputas podem ocorrer, tendo em vista a possibilidade de a informação 
conter erros e as tentativas de transferências desses erros. Dessa forma, para o autor, se as informações são incompletas, direitos individuais não são claramente delineados A informação incompleta abre espaço para que parte de atributos, de produto ou processo, precisem ser negociados para que sejam remunerados, caracterizando direito econômico.

$\mathrm{Na}$ visão de Barzel (2005), avaliações custosas de informação refletem em relutância para a obtenção de um produto. Nesse caso, a instituição de garantias implica na redução de incertezas que são por si mesmas custosas, porque podem ser detectadas adulterações nos produtos (BARZEL, 2005; ITO; ZYLBERSZTAJN, 2016). A garantia, segundo Barzel (2005), compensará os efeitos gerados por problemas informacionais, já que, sem a garantia, um comprador não assegurará as condições ótimas na obtenção de seus produtos. Portanto, a garantia indica que o produtor assume a variabilidade dos valores do produto, e alivia o consumidor da necessidade de mensuração no tempo da transação (BARZEL, 2005).

Dessa forma, a informação e seu custo não devem ser desprezados no campo da análise institucional. A dificuldade de mensurar e dimensionar as informações determina o tipo de relação entre os agentes, uma vez que, à medida que forem extremamente custosas as informações sobre os atributos de um bem, os direitos de propriedade poderão ser mal definidos e os custos de transação, significativos.

\section{PROCEDIMENTOS METODOLÓGICOS}

Em adequação ao objetivo estabelecido, realizou-se uma pesquisa de natureza qualitativa, descritiva e com recorte transversal nos anos de 2015 e 2016. Foram objetos de estudo as montadoras de automóveis e comerciais leves localizadas no estado do Paraná e alguns de seus fornecedores diretos. $\mathrm{O}$ Paraná é classificado como o terceiro polo automotivo do Brasil, após São Paulo e Rio Grande do Sul, apresentando três montadoras de automóveis e comerciais leves, localizadas em São José dos Pinhais, (ASSOCIAÇÃO NACIONAL DOS FABRICANTES DE VEÍCULOS AUTOMOTIVOS [ANFAVEA], 2017).

A pesquisa foi realizada em três fases. $\mathrm{Na}$ primeira, foram delineados $\mathrm{o}$ problema e o objetivo da pesquisa, bem como foi elaborado o referencial teórico e 
os procedimentos metodológicos a serem adotados. Na sequência, conforme detalhado na seção 3.1, realizou-se a pesquisa de campo, com o levantamento de dados primários. Na última fase, os dados primários foram trabalhados, interpretados, analisados e discutidos, dando respaldo para as conclusões apresentadas.

Após concluída a primeira fase, realizou-se a coleta de dados, por meio de entrevistas semiestruturadas com os gerentes de compras, de qualidade e de logística das três montadoras presentes no Estado. A seleção desses gerentes se justificou pela relevância dessas áreas na relação com os fornecedores diretos de autopeças. Também foram entrevistados os gerentes de logística de sete empresas fornecedoras diretas, uma vez que são os gestores que mais tem contato com as montadoras. Foram selecionados os fornecedores com maior tempo de relacionamento com as montadoras. Também foram entrevistados os coordenadores da área industrial e da área automotiva da Federação das Indústrias do Estado do Paraná (FIEP), caracterizados como agentes-chave, além de apresentarem uma visão sistêmica e imparcial do setor. Observa-se que todos os entrevistados, no total de quinze pessoas, apresentavam mais de dez anos de experiência na área, indicando sua capacidade de contribuir com o estudo.

As entrevistas foram realizadas no último semestre de 2015 e o primeiro e segundo semestre de 2016, na sede das montadoras e empresas fornecedoras, e na planta da FIEP, localizadas na região de São José dos Pinhais (Paraná), e complementadas por e-mails, mensagem e telefone. Ademais, como a área de compras de uma das montadoras é centralizada em São Paulo, a entrevista com o seu responsável foi realizada na sede da montadora nessa cidade.

As entrevistas somaram vinte horas de gravação e foram transcritas, apresentando-se disponíveis em meio eletrônico. Foram construídos dois roteiros específicos: um direcionado para os gerentes das montadoras e para os coordenadores da FIEP; outro para os gerentes das empresas fornecedoras. Esses roteiros foram elaborados e organizados em três grupos de questões. O primeiro foi direcionado a caracterização das empresas investigadas, envolvendo, especialmente, características dos produtos contratados. Os aspectos relacionados à mensuração, com desdobramentos para direitos de propriedade e informação, compuseram o segundo conjunto de questões. No terceiro conjunto, agregaram-se questões que tratavam diretamente da mensuração das 
autopeças transacionadas e sua relação com as estruturas de governança escolhidas, visando a responder ao objetivo proposto. Os dados secundários foram coletados por meio de sites e instituições especializadas no tratamento de dados do setor, como ANFAVEA, e de estudos que discutiram a sua dinâmica.

Para análise de dados foi utilizada a técnica de análise de conteúdo de Bardin (2004), que identifica três etapas básicas, adaptadas para esse estudo: pré-análise, exploração do material e interpretação inferencial. A pré-análise é a fase de organização do material obtido através da coleta de dados, sendo que, nessa etapa, foram realizadas a transcrição e leitura das entrevistas. $\mathrm{Na}$ fase de exploração do material é realizado um estudo aprofundado do material coletado através de atividades de codificação (BARDIN, 2004). A codificação, na presente investigação, foi utilizada para agrupar as unidades de fala dentro das categorias previamente estabelecidas, tendo como base a discussão da TCM, feita por Barzel (1997), quais sejam: mensuração, direitos de propriedade e informação.

A terceira fase do método de análise de conteúdo, expressa por Bardin
(2004), é a interpretação inferencial, em que se busca fazer inferências e interpretações dos dados tratados. Nesse sentido, a análise de dados foi realizada, de modo a comparar os dados obtidos para cada uma das categorias, com o referencial teórico discutido, visando compreender a influência da mensuração, dos direitos de propriedade e da informação sobre as estruturas de governança e atender ao objetivo proposto. Destaca-se que, em todos os momentos da presente investigação, buscou-se atender as indicações de Reay (2014) quanto ao delineamento de pesquisas qualitativas, ou seja, buscou-se qualidade nos dados obtidos, uso de literatura relevante e descrição detalhada dos procedimentos e dados.

\section{ANÁLISE DOS DADOS}

Visando a cumprir o objetivo proposto, é feita, nesta seção, uma análise teórico-empírica das categorias, relacionadas à mensuração, direitos de propriedade e informação. Buscou-se compreender como essas categorias se apresentaram individualmente no setor e, na sequência, como influenciaram a formação das estruturas de governança. 


\subsection{Mensuração}

A partir das entrevistas realizadas, foi possível identificar que as autopeças transacionadas entre montadoras e seus fornecedores diretos apresentam diversas dimensões mensuráveis, relacionadas à quantidade, peso, medidas, especificações técnicas e de qualidade do projeto. Esse detalhamento é imprescindível para que as montadoras possam comparar a conformidade das autopeças compradas com o que foi inicialmente acordado e contratado. Apesar do departamento de compras ser responsável pela seleção dos fornecedores e aquisição das peças, é o departamento de qualidade que controla, testa (por amostragem) e audita as suas dimensões mensuráveis. Ao departamento de logística cabe "puxar" as autopeças e as colocar na linha de produção.

Foi possível identificar uma série de etapas ou critérios para realizar o controle necessário sobre a mensuração dos atributos das autopeças transacionadas. Elas estão relacionadas: à escolha do fornecedor; ao desenvolvimento do projeto da autopeça; à fabricação da autopeça; à entrega da autopeça; ao nível de controle.

Nessa linha, constatou-se que os aspectos de mensuração já são estabelecidos desde a escolha do fornecedor. De acordo com os entrevistados, tanto das montadoras como das empresas fornecedoras, as principais exigências para seleção de fornecedores são: a apresentação das certificações ISO TS, ISO 9000, ISO 9001, ISO 14000, ISO 26000 MMOG/LE (Materials Management Operating Guideline/Logistics Evaluation - diretrizes relacionadas à gestão de materiais e logística, criada pela Automotive Industry Action Group (AIAG)) e a Material Plant Quality Program (MPQP). Conforme o Coordenador de Desenvolvimento Industrial da FIEP, esses certificados também servem para as montadoras rastrearem e mensurarem a qualidade do fornecedor: "Até pela exigência de qualidade na entrega do produto, essas grandes empresas precisam ter garantias de que o fornecedor vai atendê-las. As ISOs facilitam esse rastreamento e monitoramento dos fornecedores".

Além disso, no sourcing, realizado pela montadora para escolher o melhor fornecedor para executar o projeto da peça, são analisados aspectos de QCD (iniciais em Francês de qualité, coût e date limite), relacionados à qualidade, custo e prazo. Além disso, é passado um caderno de encargos, em que são estabelecidos os aspectos mensuráveis da autopeça a ser adquirida, tais como "volume, dimensão, 
função, especificação de pressão, de vazão, de temperatura, de volume, de altura, largura" (fala do Gerente de Logística da Empresa Fornecedora 6). O fornecedor que melhor atender as exigências de QCD, e aos critérios de mensuração especificados pela montadora, efetiva o contrato de fornecimento.

Quando o fornecedor é escolhido, dá-se início ao desenvolvimento do projeto das autopeças do carro a ser lançado. De acordo com os entrevistados, um projeto normalmente demora dois anos para ser finalizado. Nesse intervalo de tempo a montadora já desenvolve, individualmente ou com fornecedores, as autopeças que comporão a estrutura do carro. Simultaneamente ao desenvolvimento das autopeças, testes iniciais (de rodagem e de segurança nos freios, pneus, entre outros) são feitos para se avaliar as mudanças que necessitam ser realizadas no projeto, bem como na planta do fornecedor.

Embora a montadora não seja responsável pela fabricação de grande parte das autopeças, cabe a ela a definição, validação e controle de suas especificações, o que culmina numa fase de montagem teste do automóvel. O Gerente de Logística da Montadora C ratifica a unanimidade entre os entrevistados acerca desse procedimento:
"O carro teste passa na linha com as peças e já se percebe as alterações necessárias [...]. Não é um produto que o fornecedor faz e não temos conhecimento, na verdade, é um produto que ele só faz porque quase sempre nós passamos um pré-projeto para ele de como deve ser".

Durante a fase do projeto do carro, a produção de cada autopeça passa por um sistema de validação, com uma montagem teste do automóvel. Assim, antes de começar a fabricação continua é realizada a engenharia do produto, seguida pela engenharia do processo, para adequar o desenho e processo de fabricação do produto ao projeto inicialmente desenhado. Esse processo pode ser visualizado nas palavras da Gerente de Logística da Montadora A-B: "Tudo tem que ser validado na fase do projeto, então quando o carro vai virar série tem uma validação de toda a engenharia da montadora, de todo fabricante".

Assim, a partir da fabricação de um primeiro modelo da autopeça pelo fornecedor, reajustes, tanto de custos como de especificações, podem ser realizados. $\mathrm{O}$ Gerente de Compras da Montadora A-B explica: "A gente tem um projeto da peça e passa para o fornecedor. Se o peso que nós passamos para eles for menor que o peso que eles passaram para nós depois, ou qualquer outro caso, nós temos que fazer 
reajuste do preço ou de medidas, mas nós sempre conseguimos controlar isso". Além disso, conforme os entrevistados, a montadora também fornece um adiantamento, em termos de pagamento, para o fornecedor adquirir as matériasprimas (aço, alumínio, ferro, dentro outros) a serem utilizadas.

Quando ocorre a aprovação do projeto, aspectos de mensuração continuam a ser controlados durante a fabricação da autopeça $_{s}$ começada pelo fornecedor para atender o início do processo produtivo do carro na linha de produção. Nessa fase, a contratação ocorre juntamente com uma maior conformação e adaptação do projeto ao modelo real do automóvel. Para os entrevistados, a mensuração é refinada e contribui para que possíveis problemas sejam averiguados e resolvidos ao longo da montagem do carro na linha de produção. Além das medidas e especificações técnicas do produto, são determinadas a quantidade de autopeças por embalagem, o custo, das autopeças e das embalagens, o peso, a logística utilizada para atender o prazo de entrega, dentre outros. O Gerente de Qualidade da Montadora A-B detalha: “[...] Internamente, tem-se uma fiscalização por lote. Então, se começa a dar um problema, a montadora vê qual lote foi, se foi por peso, quantidade, tamanho, para descontar ou cobrar do fornecedor, e para ele se atentar para não acontecer mais".

Vale destacar que as montadoras normalmente pedem uma amostra de autopeças para realizar a conferência, antes da entrega: "Nós temos um laboratório interno que fiscaliza isso, eu mando para o laboratório e é feito uma análise. Isso acontece muito para verificar peça cromada, a composição do cromado" (Gerente de Compras da Montadora A-B).

As entregas das autopeças são feitas de acordo com o volume de carros produzidos diariamente, sendo assim, cada fornecedor é responsável por um volume fixo de fornecimento diário ou semanal. Dessa forma, a grande maioria das peças é controlada por quantidade, como destaca o gerente de qualidade da Montadora A-B: "A maioria do controle é por unidade. No pedido de compras que é encaminhado ao fornecedor, a montadora diz quantas peças precisa, o prazo e por quanto tempo. Todo o projeto técnico do produto, com todas as especificações e medidas também é detalhado". As entregas, por sua vez, são feitas em lotes e são puxadas (sistema just in time) pelas montadoras, de acordo com a sua previsão de vendas, apresentando lotes fechados ou que podem variar em termos de quantidade.

Nota-se que, em casos de atrasos na entrega, é cobrada uma multa considerando 
a quantidade de carros que se deixa de produzir em função do atraso, sendo que, conforme os entrevistados, o prejuízo do fornecedor é bem maior do que o valor referente às autopeças não entregues. Para calcular esse prejuízo, alguns cálculos especificados nos contratos são realizados, considerando-se as dimensões mensuráveis envolvendo a autopeça transacionada (valor do tempo perdido, da mão-de-obra parada, quantidade de carros, dentre outros). O Gerente de Compras da Montadora $\mathrm{C}$ explica esse procedimento, comum a todos os entrevistados:

[...] a gente utiliza uma conta da NASA, em que você tem que contar tudo separado: tempo, funcionários, custo hora. Se ficar parado 1 hora, aí faz toda uma conta de quantos empregados tem no setor, que área parou, quantos carros deixaram de ser produzidos, e o fornecedor responsável pode pagar milhões, mesmo se a peça que ele fornecer custar dez centavos. Mas é porque cada minuto você produz um carro.

\section{Destaca-se que o nível de controle} na mensuração também é específico para cada tipo de peça. Algumas autopeças necessitam de um controle de qualidade mais rígido e são testadas pelas montadoras antes de sair da linha de produção dos fornecedores. Isso pelo prejuízo que causariam, caso defeitos fossem constatados após a sua inserção nos veículos montados. Normalmente essas peças tem o embarque controlado, como explica o Gerente de Compras da Montadora C: “[...] Em algumas peças, fica uma pessoa da montadora lá na ponta da linha do cara e controla tudo. Só sai com a assinatura dessa pessoa”. Já para peças que não são consideradas críticas para o funcionamento e segurança do automóvel, o controle pode ser menos restritivo, pois não interferem diretamente na qualidade do veículo.

Sendo assim, nem todas as transações têm todas as suas dimensões mensuradas, sendo escolhidas as transações com produtos e fornecedores que apresentam maior importância para a montadora. A forma como essa escolha se dá é explicada pelo Gerente de Compras da Montadora A-B: "Então, a gente pega nossos fornecedores de maior impacto, tipo uma curva $\mathrm{ABC}$, e mede eles, porque não dá para fazer isso para tudo”. O grande porte das montadoras e a quantidade de veículos produzidos diariamente também dificultam a mensuração de todo o processo, como afirma o Gerente de Qualidade da Montadora C: "É impossível controlar tudo. São 4 mil e poucas peças por carro, faço 3500 carros por dia”.

Além disso, os entrevistados afirmaram que $\mathrm{o}$ fornecedor deve 
apresentar controles diários e ficar responsável pela qualidade dos produtos enviados para montadora, bem como pelo descarte das peças defeituosas. Para algumas peças, é previsto um percentual de descarte, que já é considerado pela montadora no contrato, como afirma o Gerente de Qualidade da Montadora A-B: "A cada 100 que ele faz, eu já pago para ele o descarte de $15 \%$ [...], porque eu sei que esse tipo de processo tem uma perda de $15 \%$. Isso já tá no contrato, se ele perder mais é problema dele. Se ele perder menos ele ganha". Entretanto, em algumas situações o processo de mensuração se torna inviável, pois trata de insumos intermediários que se perdem ao longo do processo. Um exemplo é dado pelo Gerente de Compras da Montadora A-B:

Vamos citar um exemplo: energia elétrica. Você sabe que o governo reduziu o custo de energia elétrica, então era para o fornecedor reduzir o preço da peça. Só que nós não sabemos quanto o fornecedor gasta de energia elétrica e não consegue cobrar isso dele [...]. Então, essa baixa que o governo fez da energia elétrica não repercutiu no valor final do carro, porque tem coisas que é difícil de mensurar.

Diante do exposto, considera-se que as relações de montadoras e seus fornecedores envolvem contratos de transações de autopeças, com dimensões, ou atributos, sujeitas à mensuração, conforme Barzel (1997; 2003; 2005). Dito de outra forma, as dimensões envolvidas na transação de autopeças, tais como peso, tamanho, largura, altura, densidade, pressão, peso, cor, entre outras, podem ser identificadas, mensuradas e controladas pela montadora de forma satisfatória.

Para as montadoras e fornecedores, a mensuração caracteriza o sistema de controle, direcionado tanto para garantir o atendimento às especificações técnicas do projeto, quanto para atender a programação de produção e definir a remuneração do fornecedor. Caracteriza, ainda, o sistema de garantia de direitos de propriedade (BARZEL， 2003; CUNHA; SAES; MAINVILLE， 2015; MÉNARD; SHIRLEI, 2014; ITO; ZYLBERSZTAJN, 2016) dessas partes, visto que pagamentos e recebimentos são determinados a partir dos resultados da mensuração. De forma particular, enquanto para as montadoras a mensuração viabiliza a contratação, para os fornecedores ela serve como um instrumento para avaliar a sua capacidade de conformação às especificações técnicas exigidas, guiando a decisão de assumir novos compromissos.

Apesar das montadoras buscarem prever contratualmente grande parte dos aspectos de mensuração das autopeças 
transacionadas, a incompletude contratual está presente e pode indicar possibilidade de perda de valor (BARZEL, 1997; 2003; CALEMAN et al., 2017) CUNHA; SAES; MAINVILLE，2015; ZYLBERSZTAJN, 2005) nas transações com fornecedores. Isso porque, nem todas as dimensões podem ser identificadas, mensuradas e previstas contratualmente. Pelas colocações dos entrevistados pode-se apreender que os atributos não mensurados nas transações de autopeças não são consideráveis a ponto de estimular situações recorrentes de oportunismo implícito, previstas por Barzel (1997), Fiani (2003) e Zybersztajn (2005). Entretanto, vale destacar que situações pontuais de possibilidade de comportamento oportunista podem ocorrer.

Dois motivos podem ser identificados para justificar as ocorrências de oportunismo implícito envolvendo a mensuração: 1) Assimetria de informação, quando uma das partes é privada proprositalmente de informações acerca da correta mensuração de uma autopeça específica, permitindo a captura de renda pela outra parte (BARZEL, 2005). Por exemplo, isso pode ocorrer em situações de black-box, na qual o fornecedor é responsável pelo desenvolvimento do molde, domina o know-how do processo produtivo e fixa o valor da autopeça, sendo o custo real dos componentes desconhecido pela montadora; 2) Impossibilidade de mensurar todas as dimensões das autopeças transacionadas, implicando na possibilidade de apropriação de valor. Um exemplo relatado é o caso de informações sobre a composição e o custo real da autopeça, que podem variar sem o conhecimento da montadora.

De forma geral, nas montadoras investigadas, a eficiência dos contratos se mostrou satisfatória, uma vez que é capaz de garantir que regras ex ante sejam cumpridas, indicando a estrutura contratual como dispositivo de governança adequado. Como existe possibilidade de oportunismo implícito, esses contratos são continuamente revistos e novas dimensões de mensuração podem ser inseridas. Ainda podem ocorrer alterações nas dimensões existentes, conforme mudanças no projeto ou no processo produtivo durante a contratação. Nesse contexto, nota-se que a capacidade de controle das montadoras está associada à capacidade e precisão na identificação e monitoramento dos aspectos mensuráveis das autopeças contratadas, conforme exposto em Poppo e Zenger (1998). 


\subsection{Direitos de propriedade}

De modo geral, conforme os entrevistados, existem três situações que envolvem os direitos de propriedade das montadoras e seus fornecedores na transação de autopeças: 1) A montadora é a responsável pelo desenvolvimento do molde da autopeça e o repassa para o fornecedor realizar somente a sua fabricação; 2) A montadora apresenta sua necessidade e, a partir de um trabalho conjunto com o fornecedor, desenvolve o molde da autopeça, sendo o último responsável pela sua fabricação; 3) O fornecedor é responsável por todo o processo, desde o desenvolvimento do molde até a sua fabricação, apresentando às montadoras.

Em cada um desses casos, direitos específicos (contratuais) e residuais de controle (BARZEL, 1997; FOSS; FOSS, 2001; HART, 1995; HART; MOORE, 1990) são definidos. Em grande parte das vezes, a montadora é proprietária do molde das autopeças envolvidas na transação (situação 1). Nesse caso, em que normalmente as montadoras fazem uso de contratos de comodato, além de ter seus direitos específicos assegurados contratualmente, a propriedade sobre o molde (direito residual) favorece a montadora, dado que essa só contrata o serviço do fornecedor para a fabricação. Os contratos de comodato são de natureza temporária e a montadora não se abstém do direito de retomar os moldes quando the for conveniente. Sobre esse tipo de acordo, o Gerente de Compras da Montadora C esclarece: "É minha propriedade, mas ele fica com a posse, tem o comodato. [...] se eu quiser, dependendo da minha escolha, eu posso ou não tirar dele a hora que eu quiser e passar para um terceiro".

Nos casos em que ocorre o desenvolvimento conjunto do molde das autopeças (situação 2), direitos específicos e residuais de controle também pertencem à montadora, como explica o Gerente de Compras da Montadora $\mathrm{C}$ : "O meu contrato com o fornecedor é que essa peça e a tecnologia dela não pode ser usada para outra empresa, só para mim, é minha". Nesse caso, a montadora se beneficia dos conhecimentos do fornecedor, remunerando-o pelo know-how utilizado. Esse trabalho conjunto garante ao fornecedor a possibilidade de assumir a fabricação futura da peça, embora a montadora também tenha direito contratual e residual de repassar essa função para outro fornecedor, caso o mesmo não satisfaça os requisitos de produção. Isso pode acontecer, notadamente, nos casos em que os fornecedores causam problemas de 
entrega e qualidade ou ameaçam aumentar os preços.

Como se tratam de montadoras e carros internacionais, a montadora pode desenvolver inicialmente a peça, na sua planta matriz, e enviá-la para suas filiais ao redor do mundo. Cabe a montadora filial encontrar o fornecedor adequado para executar o projeto com sua parceria. A montadora normalmente tem uma equipe técnica para dar suporte e acompanhar o fornecedor. Percebe-se, portanto, que tanto no desenvolvimento do molde pela montadora, quanto no desenvolvimento conjunto, a propriedade da autopeça permanece com a montadora.

Nos casos em que o fornecedor é responsável pelo desenvolvimento do molde das autopeças (situação 3), embora as montadoras possam exercer direitos específicos de controle, o direito residual de controle, ou seja, a propriedade da autopeça, é do fornecedor. Como consequência, os benefícios associados à transação, como preferência na comercialização, redução de custo, maior controle e possibilidade de lucro (notadamente nos casos de peças blackbox) ficam com o fornecedor. Esses últimos benefícios são exemplificados na fala do Gerente de Compras da Montadora C: "Você fala: 'Eu quero um rádio que tenha botão tal, função tal'. O que tem lá dentro não interessa. Então existe esse tipo de situação do fornecedor desenvolver algo. Aí esse rádio ele pode fazer igual para quem ele quiser"

Vale notar que, dos três tipos de desenvolvimento envolvendo montadoras e fornecedores, citados acima, o tipo mais comum é o desenvolvimento em conjunto. Percebe-se que, como as transações de autopeças das montadoras com seus fornecedores, em grande parte, tem dimensões claras e bem definidas, consequentemente os direitos de propriedade são adequadamente delimitados, conforme descrito em Barzel (1997; 2003) e Zylbersztajn (2009, p. 401). Ao transacionar a produção de uma autopeça com um fornecedor, observa-se que a montadora negocia um conjunto de direitos de propriedade sobre a autopeça que será fabricada, nos temos de Foss e Foss (2004), Barzel (2005) e Zylbersztajn (2009). Portanto, a montadora adquire o pacote inteiro de direitos de propriedade sobre a autopeça em si, como o direito para usar, vender e alugar.

Nesses termos, as montadoras adquirem os direitos específicos de controle, assegurados pela via contratual (BARZEL, 1997; FOSS; FOSS, 2001; HART, 1995; HART; MOORE, 1990;), especificamente por contratos de comodato. As montadoras adquirem, 
também, direitos residuais de controle (ALMEIDA; ZYLBERSZTAJN，2011; FOSS; FOSS, 2004; HART, 1995; HART; MOORE, 1990), pela propriedade e controle de grande parte dos moldes de autopeças. Dito de outra forma, ela tem não somente o direito de usar as autopeças, mas também de decidir quando, como e por quanto tempo o fornecedor irá fabricálas. Nesses termos, com exceção dos moldes de autopeças desenvolvidos pelo fornecedor, a montadora adquire a propriedade legalmente garantida das autopeças e pode decidir sobre seu uso em contingências não contratadas, adquirindo melhores condições de obter renda.

\subsection{Informação}

Como já destacado por Barzel (2005), a informação se estabelece como essencial para garantia dos direitos de propriedade, uma vez que mune as partes do conhecimento necessário para se engajar em uma transação e evitar a apropriação indevida de renda. Nesse aspecto, a partir das entrevistas realizadas, constatou-se que a disponibilidade de informação minimiza problemas envolvendo a racionalidade limitada e a assimetria de informação entre montadoras e seus fornecedores. Com isso, custos de transação relacionados à garantia de direito econômico, ou seja, acordos informais garantidos privadamente (BARZEL, 2003; 2005; HART, 1995), são evitados ou reduzidos. De forma mais ampla, a disponibilidade de informações está associada a: minimizar problemas nas transações; controlar a cadeia produtiva; otimizar a mensuração; gerar confiança.

Segundo os entrevistados, quanto maior for o compartilhamento de informação entre montadoras e seus fornecedores, menor a probabilidade de ocorrer problemas no desenvolvimento e fornecimento de autopeças. Conforme os entrevistados, a informação é compartilhada quando o desejo de ambas as partes é realizar o molde e o processo produtivo da maneira mais eficiente. $\mathrm{O}$ Gerente de Compras da Montadora A-B esclarece: "O fornecedor vai ter uma parcela de responsabilidade, ou no desenvolvimento ou na fabricação da peça. Às vezes, ele é especialista naquilo e acaba passando para nós o conhecimento do processo. Às vezes, o nosso conhecimento é maior, mas isso sempre contribui". Dessa forma, a disponibilidade de informações associada a relações recorrentes contribui para a criação de um ambiente de confiança em que a solução de problemas se torna eficaz. 
Ademais, a informação permite o controle sobre vários aspectos da cadeia produtiva. Algumas vezes, o controle sobre as informações e sobre o processo é tão alto que as montadoras se responsabilizam pela cadeia de suprimentos de seus fornecedores diretos. Isso normalmente acontece quando a montadora realiza a compra das matériasprimas que compõem os módulos feitos pelos fornecedores, como explica o Gerente de Qualidade da Montadora C: “[...] muitas vezes é a montadora quem compra, paga a mão de obra para o cara montar a peça e ele só entrega o módulo. Ela tem controle sobre todas as informações desse processo, o fornecedor entra só para fazer mesmo". Os gerentes entrevistados afirmam que o controle sobre a cadeia produtiva pode acarretar vantagens, pois, além de garantir a qualidade da matéria-prima da sua cadeia de fornecimento, normalmente as montadoras compram altos volumes, conseguindo melhores preços. Portanto, a disponibilidade de informações viabiliza a coordenação e o controle da cadeia produtiva, garantindo a qualidade da autopeça final, sem incorrer em elevados custos de transação, dado a identificação das partes.

Outro aspecto relacionado à disponibilidade de informações nas transações realizadas se configura na própria mensuração. No setor, observouse, por meio das entrevistas, que o processo de mensuração é recorrente, tendo como consequência natural a geração de informação. Nesse aspecto, a mensuração se constitui em um tipo de informação, ou seja, ela alimenta o sistema de informação, como proposto por Barzel (2005). A obtenção da mensuração orienta não só procedimentos operacionais quantos aspectos econômicos (pagamentos, descontos, investimentos) das transações. Por outro lado, a informação também alimenta o processo de mensuração, indicando ou demandando as mensurações necessárias para ratificar os compromissos firmados entre as partes, permitindo sua condução e renovação. O Gerente de Qualidade da Montadora A-B afirma: “O histórico de relacionamento com o fornecedor já nos fornece informação para saber o que cobrar dele, como, quanto e quando cobrar. A gente vai aprendendo a cada transação [...]".

A geração de confiança também se apresentou como um resultado de um sistema estruturado de informações. A confiança é construída por meio da rastreabilidade gerada no processo de desenvolvimento, fabricação e entrega das autopeças, dado o monitoramento de critérios de quantidade, qualidade, custo e 
prazo de entrega presentes no histórico das relações. Cabe observar que todas as informações relacionadas ao veículo (componentes utilizados, número de lotes, de chassis, quantidade por lote, fornecedores, dentre outras), produzidas internamente ou fornecidas, deve constar em uma ficha de rastreabilidade, que fica arquivada e disponível para acesso, por lei (VPK), por dez anos.

Percebe-se, portanto, que a disponibilidade e qualidade das informações obtidas pelas montadoras e fornecedores permitem minimizar problemas nas transações, controlar a cadeia produtiva, sustentar os mecanismos de mensuração, bem como gerar confiança no processo produtivo. Notou-se que, no caso das transações de autopeças, não são observadas relutâncias por parte dos fornecedores, relacionadas a avaliações custosas de informações para as montadoras, nos termos propostos por Barzel (2005), Cheremukhn, Popova e Tutino (2015), North (2016) e Vazquez e Hallack (2015). Ademais, a garantia oferecida minimiza conflitos ou incertezas sobre o fornecimento (qualidade e prazo de entrega), compensando os efeitos gerados por problemas informacionais (BARZEL, 2005).

Notou-se que a informação dá significado à posse, pois indica as autopeças que estão sendo transacionadas e em que condições. Isso corrobora o exposto por Barzel (2005), de que os direitos de propriedade são altamente influenciados pela informação que se tem sobre os aspectos que envolvem as transações de bens. Esses problemas relacionados a informações normalmente são resolvidos pelo direito econômico, ou seja, acordos informais entre montadoras e seus fornecedores, considerando, entretanto, que já são inicialmente respaldados pelas garantias oferecidas contratualmente (direito legal), conforme propõe Barzel (2005).

\subsection{Estruturas de governança e custos de mensuração}

A consideração de aspectos teóricos da TCM, relacionados a mensuração, direitos de propriedade e mensuração, permite justificar as estruturas de governança estabelecidas pelas montadoras para coordenar suas transações nas relações com fornecedores de autopeças.

A integração vertical ocorre no desenvolvimento do design, na fabricação do motor, na estamparia de algumas partes, na pintura e, em alguns casos, na produção do câmbio. Ao se considerar a proposta de Barzel (1997; 2003; 2005), constata-se que a dificuldade e a complexidade de 
mensuração dos atributos dessas autopeças e atividades justificam a opção pela integração vertical. Isso porque, tal complexidade poderia estabelecer situações de incompletude contratual com possibilidades de perda de valor, caso se optasse pela contratação, corroborando o exposto em Barzel (2005) e Ménard e Shirlei (2014).

As dificuldades de acesso aos componentes (parte interna do motor e câmbio) e de medir aspectos intangíveis que formam a identidade da marca (design, estamparia e pintura) justificam o controle da execução dessas partes pela hierarquia. Paralelamente, o controle desses itens fora da montadora dificultaria a garantia de direitos de propriedade, uma vez que nem todas as informações estariam disponíveis. Embora a montadora pudesse obter direito específico (contratual) e residual de controle, na prática sua posse seria limitada por não ter como identificar e controlar todos os aspectos mensuráveis envolvidos.

Para as demais autopeças necessárias à fabricação do automóvel, a utilização dos contratos se mostra adequada, devido a condição satisfatória da mensuração em garantir direitos de propriedade, corroborando Barzel (1997; 2002; 2003) e Poppo e Zenger (1998). Sendo assim, além de diminuir os custos gerenciais e operacionais utilizando empresas fornecedoras, como indicado por Hart e Moore (1990), as montadoras conseguem manter direitos específicos (contratuais) e residuais de controle (propriedade do ativo), não necessitando incorrer nos custos extras da integração vertical. A opção pela contratação é fortalecida, ainda, porque as partes se relacionam diretamente e buscam desenvolver confiança e reputação para firmar relações de longo prazo, benéficas para ambos os lados (BARZEL, 2005; CROOK et al., 2013; CUNHA; SAES; MAINVILLE, 2015).

A estrutura de governança via mercado spot não foi observada a partir das entrevistas realizadas. Isso porque, essa forma de governança limita o sistema de garantias (Barzel, 2002; 2005) necessário para as transações de ativos específicos, uma vez que não há um sistema de controle efetivo. Nesse caso, embora o direito legal seja acessível na resolução de problemas, ele oferece apenas garantias parciais, cabendo a montadora a responsabilidade final sobre o produto comercializado e rastreabilidade das peças. Ademais, considerando o arcabouço teórico da TCM (BARZEL, 1997; 2003; 2005), a necessidade de mensuração, de proteção dos direitos de propriedade e de obtenção de informações, torna a relação 
via mercado inadequada, dado a especificidade das autopeças envolvidas nas transações e a obtenção de garantias.

Dessa forma, a partir da TCM, observou-se que a escolha da integração vertical e de formas contratuais nas montadoras investigadas encontra respaldo em Barzel (1997; 2002; 2003; 2005) e Vazquez e Hallack (2015). A integração vertical se justifica pela dificuldade de mensuração nas dimensões das autopeças, considerando o alto nível de especificidade do design, motor, estamparia, pintura e câmbio. $\mathrm{O}$ custo de se obter uma mensuração correta e abrangente desses itens poderia criar possibilidades de captura de valor (Barzel, 1997), caso o contrato fosse utilizado. Como o restante das autopeças pode alcançar nível médio ou alto de mensuração, padronização, obtenção de informação e garantias de proteção dos direitos de propriedade, sua transação ocorre pela via contratual. Nesse caso, os custos de mensuração e de transação gerados, menores que a integração vertical, compensam a terceirização. Isso porque, o direito legal, considerando as garantias apresentadas pelos fornecedores, e o direito econômico, com acordos facilitados por relações de longo prazo, sustentam as transações com benefícios para as montadoras.

\section{CONCLUSÕES}

A presente investigação discutiu as escolhas das estruturas de governança (mercado, contratos e integração vertical), considerando como objeto de estudo o setor automotivo paranaense, com foco nas relações de montadoras e seus fornecedores diretos de autopeças. Essas escolhas foram tratadas à luz da TCM, considerando, notadamente, aspectos de mensuração, direitos de propriedade e informação sobre as autopeças transacionadas.

No que tange à mensuração, observou-se que ela é possível devido aos mecanismos de controle estabelecidos, desde a escolha do fornecedor e desenvolvimento do projeto da autopeça até a sua fabricação e entrega. Envolve, ainda, o controle do tipo de autopeça, ou seja, se é crítica ou não para a interrupção do processo produtivo. Os direitos de propriedade, por sua vez, envolvem: situações em que a montadora desenvolve e é a proprietária do molde da autopeça, situações de desenvolvimento conjunto com o fornecedor, bem como situações em que esse desenvolvimento e propriedade são do fornecedor.

Em todos os casos, a montadora adquire direitos específicos de controle, 
por meio de contratos de comodato, também possuindo, nos dois primeiros casos, direitos residuais de controle, com poder sobre a autopeça na forma que lhe for conveniente. No que diz respeito às informações, sua disponibilidade mostra-se satisfatória, contribuindo para: a minimização de problemas nas transações, o controle sobre a cadeia produtiva, a otimização do próprio processo de mensuração e a geração de confiança e padronização nas relações. Dessa maneira, a possibilidade de mensuração e de definição dos direitos de propriedade das montadoras, bem como o compartilhamento de informação entre as partes justificam a forma contratual como estrutura de governança predominante e condizente com a realidade transacional do setor.

Em complemento, a integração vertical é utilizada para autopeças que apresentam características de difícil mensuração. Nesse caso, a complexidade da mensuração pode indicar perda de valor (design e qualidade da pintura e estamparia) ou, até mesmo, dificuldades para garantir a padronização interna de alguns componentes (parte interna do motor e câmbio, por exemplo), dados os custos de controle sobre a sua configuração. Essa limitação em mensurar todas as informações acerca dos componentes leva a montadora a buscar a integração vertical como mecanismo para garantir seus direitos de propriedade específicos e residuais.

No entanto, constatou-se que, ao se considerar somente a TCM, a condição estratégica do recurso deixa de ser avaliada. Notou-se que, quando se opta pela integração vertical do motor, câmbio, estamparia, pintura e design, não está em jogo apenas a dificuldade de mensurar, mas também a função desses recursos na construção do diferencial do produto transacionado e da identidade da montadora. Ademais, a TCM não considera variações no nível de especificidade de ativos transacionados, conforme propõe Williamson (1985), não tratando da variabilidade nas possibilidades de comportamentos oportunistas explícitos.

Dessa forma, mostra-se necessário aprofundar investigações sobre aspectos estratégicos e relacionados à abordagem dos custos de transação, em conjunto com a TCM. Destaca-se, ainda, que não foram implementados mecanismos de mensuração de valor de autopeças, bem como de definição quantitativa de custos de transação e mensuração, o que se pode fazer em pesquisas posteriores. Em última instância, o objetivo é que surjam novas 
questões e, com elas, novos desafios para pesquisadores que busquem avançar nas discussões sobre os fatores influenciadores das escolhas quanto às fronteiras organizacionais. 


\section{REFERÊNCIAS}

ALMEIDA, L. F.; ZYLBERSZTAJN, D.; KLEIN, P. Determinantes dos arranjos contratuais nas transações de crédito agrícola. Revista de Administração, v. 45, n. 3, p. 209-220, jul./set. 2010 .

ANFAVEA - ASSOCIAÇÃO NACIONAL DOS FABRICANTES DE VEÍCULOS AUTOMOTIVOS. Anuário da Indústria Automotiva Brasileira 2016. São Paulo, 2016. Disponível em: <http://www.anfavea.com.br/>. Acesso em: 10/10/2017.

BARZEL, Y. Economic analysis of property right. Cambridge University Press, 2.ed. 1997. $175 \mathrm{p}$.

Organization Firms and Measurement Costs. Congresso da International Society for the New Institutional Economics. Berkeley, California, 2002.

Property rights in the firm. In.: ANDERSON, T. L.; MCCHESNEY, F. S. (Eds.). Property rights: cooperation, conflict and law. New Jersey: Princeton University Press, 2003. p. 43-57.

- Organizational Forms and Measurement Costs. Journal of Institutional and Theoretical Economics, v. 161, p. 357-373, 2005.

CERRA, Aline Lamon; MAIA, Jonas Lucio. Desenvolvimento de produtos no contexto das cadeias de suprimentos do setor automobilístico. Revista de Administração Contemporânea, Curitiba, v. 12, n. 1, p. 155-176, Jan/Mar, 2008.

CAlEMAN, S.; ZYlBersZTAJN, D., PEREIRA, M. W. G.; OliVEIRA, G. M. Organizational tolerance in agro-industrial systems: an empirical application for the meat sector. Revista de Administração, n. 52, p. 456-466, 2017.

CHEREMUKHN, A.; POPOVA, A.; TUTINO, A. A theory of discrete choice with information costs. Journal of Economic Behavior \& Organization, v. 113, p. 34-50, 2015. http://dx.doi.org/10.1016/j.jebo.2015.02.022.

COASE, R. H. The Nature of the Firm. Economica, London, New Series, v. 4, n. 16, p. 386405, Nov. 1937. 
1960.

The Problem of Social Cost. Journal of Law and Economics, v. 3, p. 1-44, Oct.

COSTA, R. M.; HENKIN, H. Estratégias Competitivas e Desempenho da Indústria Automotiva no Brasil. Economia e Sociedade, Campinas, v. 25, n. 2, p. 457-487, ago. 2016.

CROOK, T. R.; COMBS, J. G.; KETCHEN JR., D. J.; AGUINIS, H. Organizing around transaction costs: What have we learned and where do we go from here? Academy of Management Perspectives, v. 27, n. 1, p. 63-79.

CUNHA, C. F.; SAES, M. S. M.; MAINVILEE, D. Y. Custo de transação e mensuração na escolha da estrutura de governança entre supermercados e produtores agrícolas convencionais e orgânicos no Brasil e nos EUA. Gestão e Produção, v. 22, n. 1, p. 67-81, 2015.

DAVID, R. J.; HAN, S. K. A Systematic Assessment of the Empirical Support for Transaction Cost Economics. Strategic Management Journal, v. 25, p. 39-58, 2014.

FERRATO, E.et al. Relacionamento Interorganizacional e Hold-Up no Setor Automotivo: Uma Análise sob o Enfoque da Economia dos Custos de Transação. Revista de Gestão USP, v. 13, n. 1, p. 75-87, Jan/Mar, São Paulo, 2006.

FERREIRA, M. P.; SERRA, F. A. R. Make or buy in a mature industry? Models of client supplier relationships under TCE and RBV perspectives. Brazilian Administration Review, v. 7, n.1, p. 22-39, 2010.

FIANI, R. A natureza multidimensional dos direitos de propriedade e os custos de transação.

Economia e Sociedade, Campinas, v.12, n.2 (21), p. 185-203, jul./dez., 2003.

FOSS, Kirsten; FOSS, Nicolai J. Assets, Attributes and Ownership. International Journal of the Economics of Business, Oxford, v. 8, n. 1, p. 19-37, 2001.

The Next Step in the Evolution of the VBR: Integration with Transaction Cost Economics. Management Revue, Mering, v. 15, n. 1, p. 107-121, Mar/2004.

GROSSMAN, S. J.; HART, O. D. The Costs and Benefits of Ownership: A Theory of Vertical and Lateral Integration. Journal of Political Economy, v. 94, n. 4, p.691-719, 1986. 
HART, O. Firms, contracts, and financial structure. Oxford University Press, Oxford, England, 1995.

ITO, N. C.; ZYKBERSZTAJN, D. Power and selection of contract terms: The case from the Brazilian orange juice sector. Revista de Administração, n. 51, n. 1, p. 5-19, 2016.

KLEIN, B.; CRAWFORD, R. G.; ALCHIAN, A. A. Vertical integration, appropriable rents, and the competitive contracting process. Journal of Law and Economics, v. 21, n. 2, p. 297326, Oct, 1978.

MAHNKE, V.; OVERBY, M. L.; VANG, J. (2005) Strategic Outsourcing of IT Services: Theoretical Stocktaking and Empirical Challenges. Industry and Innovation, v. 12, n. 2, p. 205-253, 2005.

MÉNARD, C.M.; SHIRLEI, M. M. The future of new institutional economics: from early intuitions to a new paradigm. Journal of Institutional Economics, v. 10, Special Issue 04, p. 541 - 565, December 2014.

MONTEIRO, G. F. A.; ZYLBERZSTAN, D. Direitos de Propriedade, Custos de Transação e Concorrência: o Modelo de Barzel. Economic Analysis of Law Review, Brasília, v. 2, n. 1, p. 95-114, Jan-Jun, 2011.

NORTH, D. Institutions, Institutional Change and Economic Performance. Cambridge: Cambridge University Press: 1990. 152 p.

NORTH, D. Institutions and Economic Theory. The American Economist, v. 61, n. 1, p. 72 76, 2016.

1991

Institutions. Journal of Economic Perspective, v. 5, n. 1, p. 97-112, Pittsburgh,

Custos de Transação, Instituições e Desempenho Econômico. Rio de Janeiro: Instituto Liberal, 2006.

POPPO, Laura; ZENGER, Todd. Testing alternative theories of the firm: transaction cost, knowledge-based, and measurement explanations for make-or-buy decisions in information services. Strategic Management Journal, v. 19, n.9, p. 853-877, Sep. 1998. 
REAY, T. Publishing qualitative research. Family Business Review, v. 27, n. 2, p. 95-102, 2014.

VANALLE, R. M.; SALLES, J. A. A. Relação entre montadoras e fornecedores: modelos teóricos e estudos de caso na indústria automobilística brasileira. Gestão e Produção, São Carlos, v. 18, n. 2, p. 237-250, 2011.

VAZQUEZ, M. E.; HALLAC, M. Efficiency versus Measurement Costs: Institucional Diversity in Network Industries. Economic Analysis of Law Review, v. 6, n. 2, p. 373-385, 2015.

WILLIAMSON, O. E. Markets and hierarchies: analysis and antitrust implications. New York: Free Press, 1975.

The economic institutions of capitalism: firms, markets, relational contracting. New York: Free Press, 1985.

The mechanisms of governance. New York: Oxford University Press, 1996.

- Strategy Research: Governance and Competence Perspective. Strategic Management Journal, v. 20, n. 12, p. 1087-1108, December, 1999.

The new institutional economics: taking stock, looking ahead. Journal of Economic Literatura, v. 38, p. 595-613, September, 2000.

The Theory of the Firm as Governance Structure: from choice to contract. 2002. (Working Paper).

Transaction cost economics and organization theory. HBS Conference on Organization Design. December 5-6, 2008.

ZYLBERSZTAJN, Décio. Estruturas de governança e coordenação do Agribusiness: uma aplicação da Nova Economia das Instituições. Tese de livre docência apresentada no Departamento de Administração da Faculdade de Economia, Administração e Contabilidade da Universidade de São Paulo. São Paulo: 1995.

Measurement costs and governance: bridging perspectives of transaction cost economics. In: International Society for the New Institutional Economics - ISNIE, Barcelona- Espanha, 2005. 
Papel dos contraltos na coordenação agroindustrial: um olhar além dos mercados. In: SOUZA, José Paulo de; PRADO, Ivanor Nunes do (Org.). Cadeias produtivas: estudos sobre competitividade e coordenação. 2. Ed. Maringá: EDUEM, 2009. 